\title{
Transcriptional regulatory role of NELL2 in preproenkephalin gene expression
}

Han Rae Kim ${ }^{\mathrm{a}, \mathrm{b} \dagger}$, Dong Hee Kim ${ }^{\mathrm{a} \dagger}$, Chang Man $\mathrm{Ha}^{\mathrm{a}, \mathrm{c} \dagger}$, Jungil Choi ${ }^{\mathrm{a}, \mathrm{d}}$, Jeong Woo Park ${ }^{\mathrm{a}}$, Sergio R. Ojeda ${ }^{\mathrm{e}}$, Jin Kwon Jeong ${ }^{\mathrm{b}^{*}}$ and Byung Ju Lee $\mathrm{a}^{\mathrm{a}^{*}}$

${ }^{a}$ Department of Biological Sciences, University of Ulsan, Ulsan 44610, Korea, ${ }^{b}$ Department of Pharmacology and Physiology, George Washington University School of Medicine and Health Sciences, Washington, DC, 20037, USA,

${ }^{c}$ Research Division and Brain Research Core Facilities of Korea Brain Research Institute, Daegu 41068, Korea, ${ }^{d}$ Bioenvironmental Science \& Technology Division, Korea Institute of Toxicology, Jinju 52834, Korea, ${ }^{e}$ Division of Neuroscience, Oregon National Primate Research Center/Oregon Health \& Science University, Beaverton, Oregon 97006, USA

*Correspondence: Byung Ju Lee, bjlee@ulsan.ac.kr; Jin Kwon Jeong, jinkwon0911@gwu.edu

$\uparrow$ These authors have contributed equally to this work and share first authorship.

Running title: NELL2 actions on preproenkephalin gene expression 
Abstract: Preproenkephalin (PPE) is a precursor molecule for multiple endogenous opioid peptides Leu-enkephalin (ENK) and Met-ENK, which are involved in a wide variety of modulatory functions in the nervous system. Despite the functional importance of ENK in the brain, the effect of brain-derived factor(s) on PPE expression is unknown. We report the dual effect of neural epidermal growth factor (EGF)-like-like 2 (NELL2) on PPE gene expression. In cultured NIH3T3 cells, transfection of NELL2 expression vectors induced an inhibition of PPE transcription intracellularly, in parallel with downregulation of protein kinase C signaling pathways and extracellular signal-regulated kinase. Interestingly, these phenomena were reversed when synthetic NELL2 was administered extracellularly. The in vivo disruption of NELL2 synthesis resulted in an increase in PPE mRNA level in the rat brain, suggesting that the inhibitory action of intracellular NELL2 predominates the activation effect of extracellular NELL2 on PPE gene expression in the brain. Biochemical and molecular studies with mutant NELL2 structures further demonstrated the critical role of EGF-like repeat domains in NELL2 for regulation of PPE transcription. These are the first results to reveal the spatio-specific role of NELL2 in the homeostatic regulation of PPE gene expression.

Key words: NELL2, Preproenkephalin, Endoplasmic reticulum, Calcium ion, Protein kinase C, Extracellular signal-regulated kinase (ERK) 


\section{Introduction}

Enkephalins (ENKs) are endogenous opioid peptides that are involved in a wide variety of physiological systems including cardiovascular system, thirst and feeding, analgesia, gastrointestinal functions $[1,2]$. In the brain, ENKs are neuromodulators involved in motivation such as drinking, feeding and reproductive behavior and emotional behavior [2, 3]. ENKs, including Leu-ENK and Met-ENK, are synthesized from a precursor protein, proenkephalin, which is translated from preproenkephalin (PPE) mRNA [4]. There is a wide distribution of ENK expression within the brain, with relatively high level observed in the hypothalamic nuclei [5]. Regulation of PPE gene transcription in the brain is multifactorial and involves neurotransmitters and blood-borne hormones including estrogen [6-9]. In parallel, other investigations have demonstrated the involvement of intracellular signaling molecules, such as protein kinase C (PKC) [9]. However, little is known about the action of brain-derived neuropeptides on regulation of PPE gene expression.

Here we report that neural epidermal growth factor (EGF)-like-like 2 (NELL2) regulates PPE gene expression in cultured NIH3T3 cells and in the rodent brain. NELL2 was identified as a PKC-interacting molecule through its EGF-like domains [10]. In support of this finding, three of six domains in NELL2 share common amino acid residues for $\mathrm{Ca}^{2+}$ binding $[11,12]$, suggesting its function in $\mathrm{Ca}^{+}$-dependent and PKC-mediated cellular events $[10,12]$. Therefore, in this context, NELL2 seemed to be an intracellular signaling molecule.

In contrast, multiple investigations have demonstrated that NELL2 is an N-glycosylated secreted protein $[10,13,14]$. Once released, NELL2 has been suggested to bind to and activate unknown receptors and subsequently modulate PKC and extracellular signalregulated kinase (ERK) pathways in target cells [13, 15-18]. Recent studies have found that this extracellular NELL2 is a novel ligand for the roundabout guidance receptors Robo 2 and Robo 3 for axon-pathfinding during neural development [19-21]. Therefore, it is likely that 
NELL2 establishes two independent routes (intracellular and extracellular) to the PKC-ERK signaling pathway.

Similar to PPE, NELL2 expression is relatively high in the hypothalamic nuclei, including the ventromedial hypothalamic nucleus (VMH), arcuate nucleus (ARC), and paraventricular nucleus (PVN) [22, 23]. Within the hypothalamus, NELL2 is one of the downstream targets of estrogen $[16,24,25]$ and is involved in sexual dimorphic brain development and behavior, as well as metabolic regulation $[14,23,25,26]$. Furthermore, because PKC is an intracellular target of NELL2 action and is a signaling mediator for PPE gene transcription, NELL2 and PPE seem to be closely correlated in regional and functional aspects.

Thus, we sought to investigate the potential of NELL2 function in the regulation of PPE gene transcription through PKC signaling. Our results demonstrate the dual effect of NELL2 in PPE gene transcription: intracellular overexpression of NELL2 resulted in a decrease in PPE promoter activity following downregulation of PKC and ERK pathways, whereas extracellular NELL2 stimulated ERK signaling and PPE gene transcription. Experiments with mutant NELL2 further demonstrate a key role of the EGF repeat domains in these processes. Together, our results are the first to indicate that both intracellular and extracellular NELL2 contribute to PPE gene transcription by functionally opposing each other in modulating the PKC-ERK pathway.

\section{Results}

\subsection{NELL2 is expressed in a subset of neurons showing enkephalinergic phenotype}

Previously, we found that NELL2 is expressed in many regions of the adult rat brain [22, $25,27]$. In particular, the forebrain regions including the $\mathrm{VMH}$, amygdala, and piriform cortex, with abundant expression of endogenous opioid peptides such as ENK [28, 29], are 
the major sites for NELL2-containing neurons [27]. Therefore, we first determined the colocalization of NELL2 and PPE in these brain regions using in situ hybridization. Our results showed abundant NELL2 mRNA signals in the mentioned brain regions containing PPE transcripts (Figure 1). To confirm our findings at a single-cell level, we performed VMH-targeted immunohistochemistry and observed that neurons positive for PPE immunoreactivity (ir) also were labeled with NELL2-ir, clearly indicating the co-presence of NELL2 and PPE in the same VMH neurons (Figure 2). These anatomical results indicate that PPE-expressing VMH cells could be targets of both intracellular and extracellular NELL2.

\section{Figure 1}
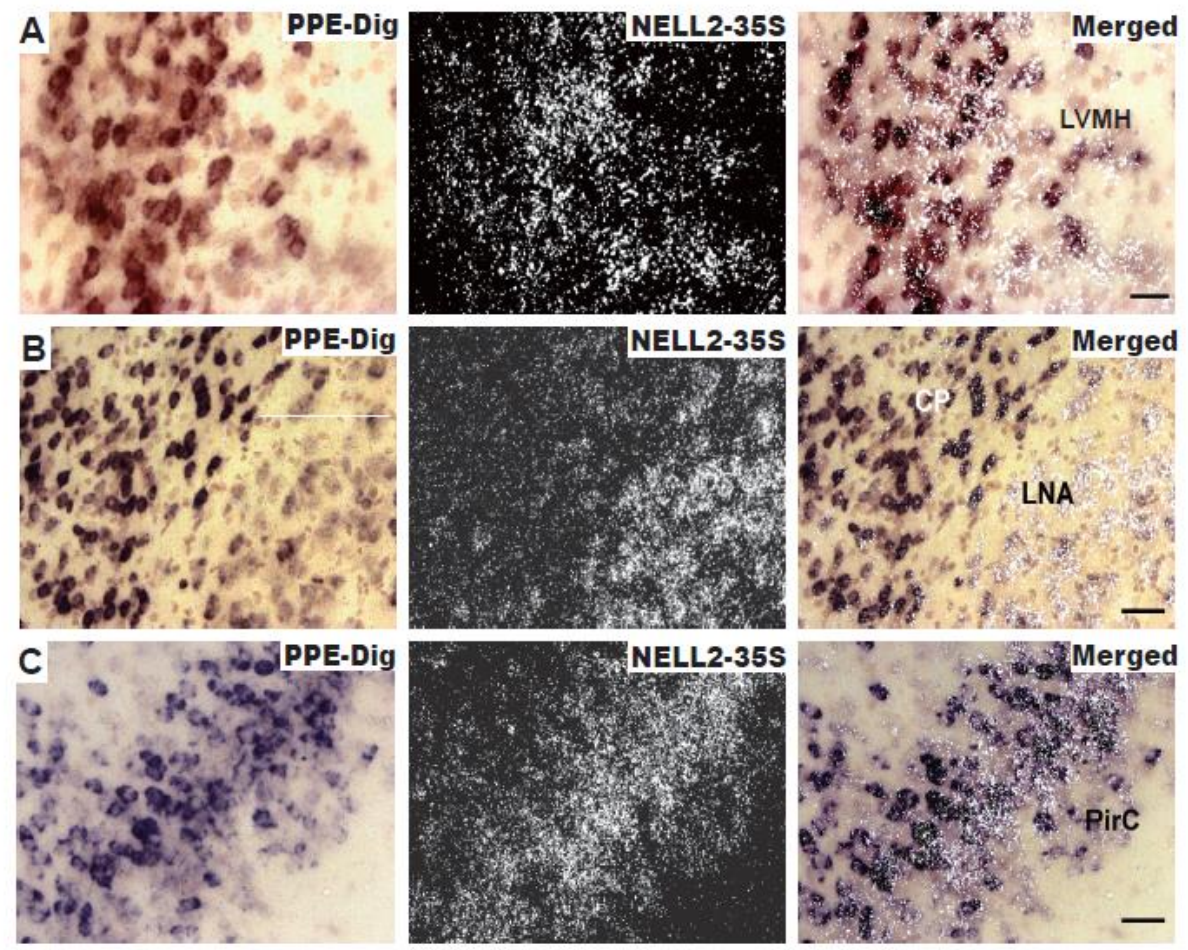


\section{Figure 2}
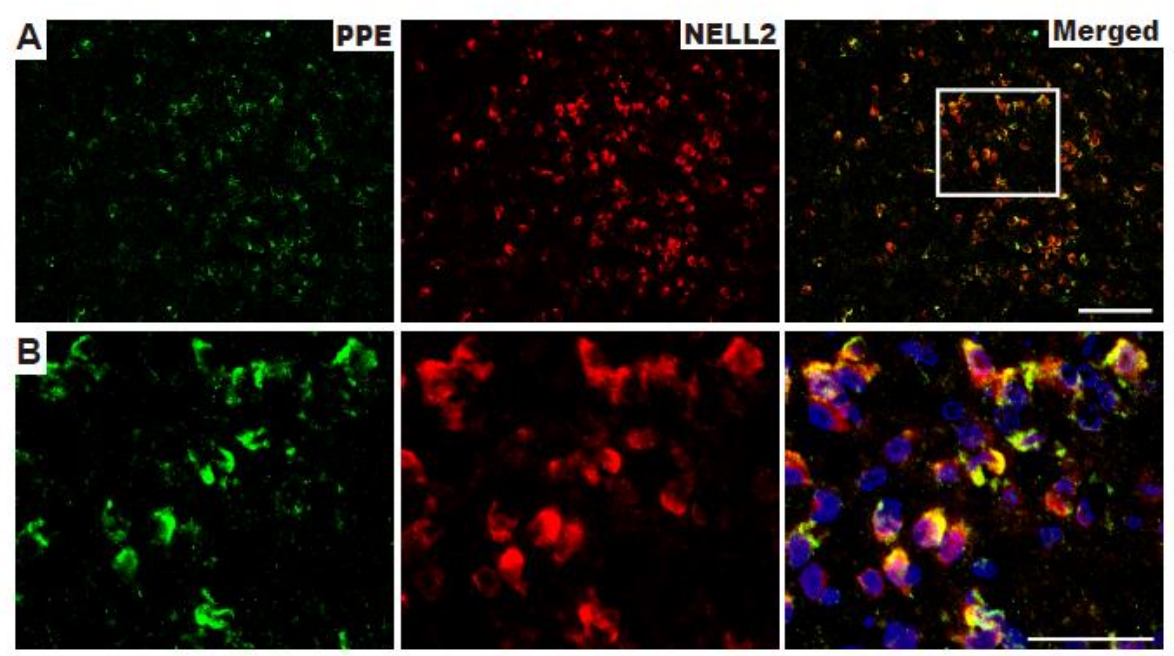

\subsection{Intracellular NELL2 suppresses PPE promoter activity}

A major focus of this study is to evaluate the potential function of NELL2 on PPE gene transcription. Therefore, we used in vitro approaches with NIH3T3 cells, as they possess endogenous machinery to synthesize ENK [30], to directly test the influence of NELL2 on PPE promoter activity. First, we tested the expressional efficiency of our PPE promoterluciferase reporter vector (PPE-Luc) in NIH3T3 cells and found that this construct is transcriptionally active over a wide range of concentrations in cultured cells (Figure 3A). Then, NIH3T3 cells were cotransfected with PPE-Luc together with different concentrations of NELL2 expression vectors, which resulted in a dose-dependent decrease in PPE-Luc activity (Figure 3B). These results are likely the reflection of the negative regulatory role of NELL2 in PPE transcription and provide the first evidence indicating NELL2 influence on PPE gene expression. Given that NELL2 can be secreted from cultured cells after transfection of NELL2 expression vector (Supplementary Figure 1A), a caveat to this experiment is that it does not allow us to pinpoint the site of NELL2 action. Therefore, we used a mutant NELL2 
(NELL2-KDEL) that carries an endoplasmic reticulum (ER) retention signal in addition to normal functional motifs $[31,32]$. In this case, mutant NELL2 will be accumulated within the cytoplasm, more specifically in the ER, of transfected cells without being released (Supplementary Figure 1B). Importantly, transfection of vectors for NELL2-KDEL into the NIH3T3 cells also induced a decrease in PPE-Luc activity (Figure 3C). In parallel, we performed an independent experiment using brefeldin A (BFA), an inhibitor for protein transfer from the ER to Golgi apparatus [33], and observed an inhibitory effect of intracellular NELL2 on PPE-Luc activity (Figure 3D; Supplementary Figure 1C). In line with these results, PPE mRNA level in the cultured cells was decreased with NELL2 expression vector (Figure 3E). Similar results were found in other cell lines (C17.2 cells; Supplementary Figure 2), indicating that these observations are not cell-type-specific. Altogether, these results suggest that intracellular NELL2 negatively influences PPE transcription. 


\section{Figure 3}

A

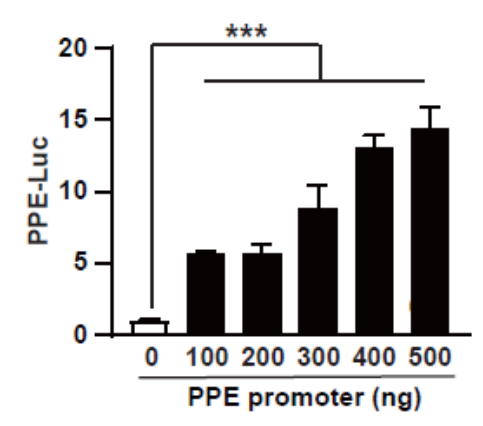

B

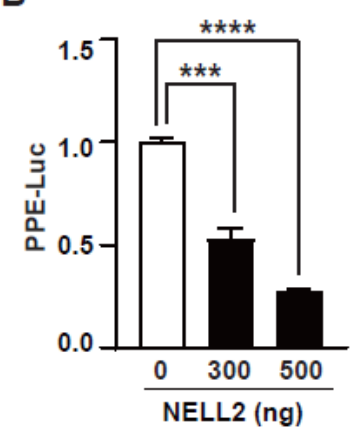

C

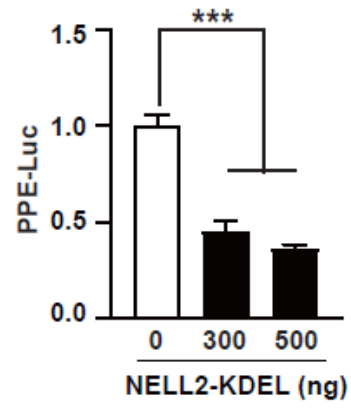

D

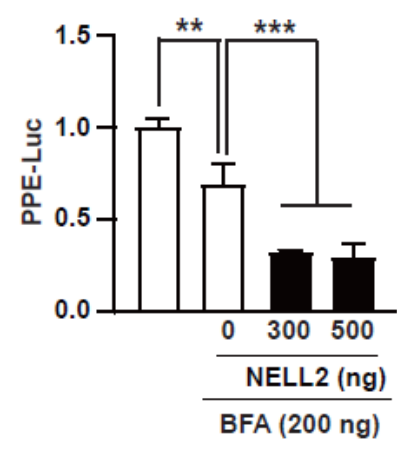

E

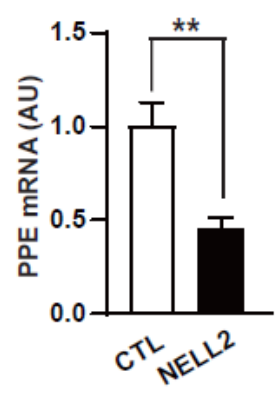

\subsection{Intracellular NELL2 inhibits PPE transcription via its EGF-like domains}

As mentioned, the NELL2 protein consists of multiple functional domains including thrombospondin-1-like (TSP-N), EGF-like repeats, and cysteine-rich von Willebrand factor C-like (CR) domains [10], presumably with differential biological functions. Therefore, we sought to investigate NELL2 domains directly related to PPE transcription. To do this, we constructed mutant NELL2 expression vectors with differential deletion of functional domains, as indicated in Figure 4A. The NIH3T3 cells were cotransfected with PPE-Luc and each naïve or mutant NELL2 expression vector. Interestingly, intracellular naïve NELL2induced inhibition of PPE-Luc activity was mitigated only with vectors for NELL2 mutants lacking the EGF-like domains such as NELL2 $\triangle \mathrm{EGF}^{-\mathrm{Ca}^{2+}}$ (lacking $\mathrm{Ca}^{2+}$-binding EGF 
domains) and NELL2 $\triangle$ EGF (lacking all EGF domains) (Figure 4B). These results indicate that the EGF domains are key to regulation of PPE transcription. Additionally, our results suggest a possible involvement of the $\mathrm{Ca}^{2+}$-dependent pathway in intracellular NELL2mediated PPE transcription.

\section{Figure 4}
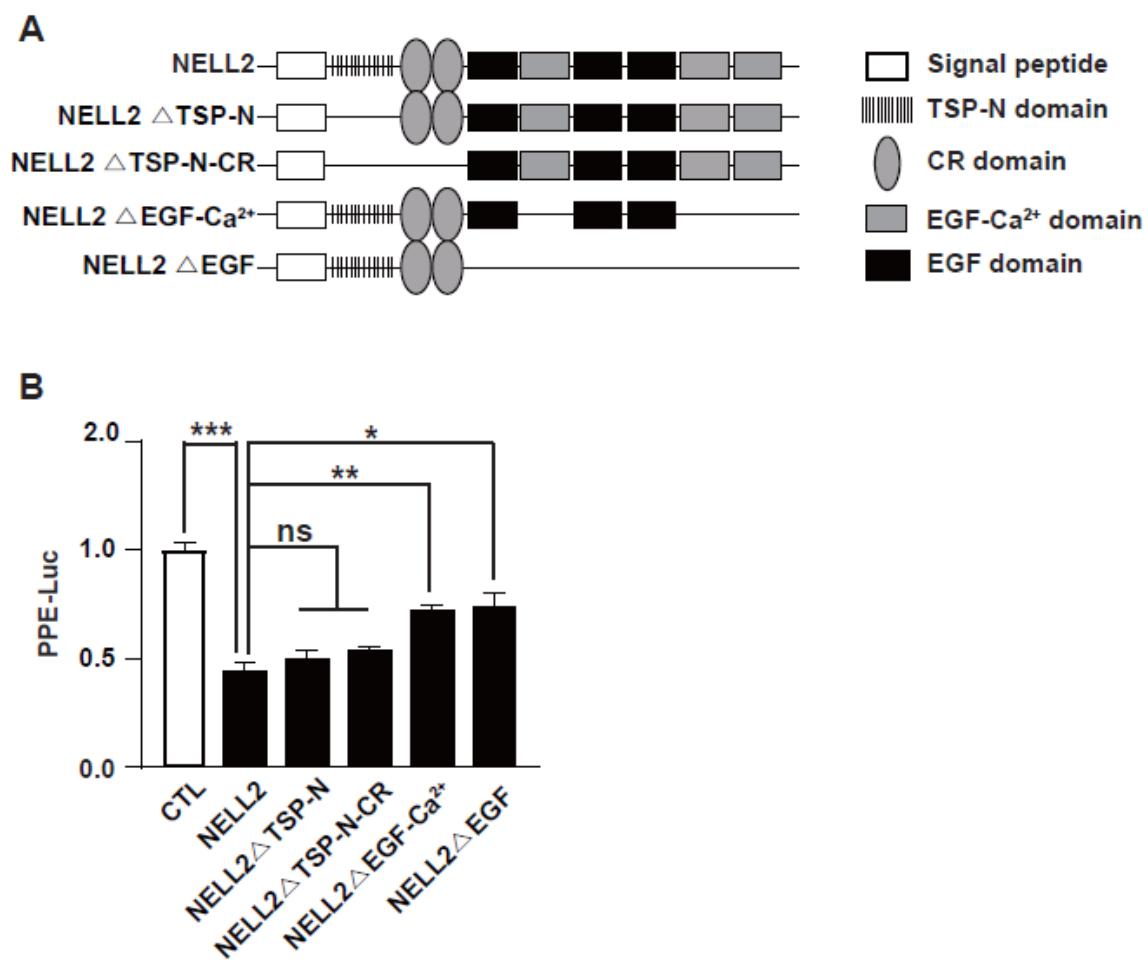

2.4. Intracellular NELL2 suppresses PPE transcription via the Ca ${ }^{2+}-P K C-E R K-c F o s$ pathway

We next sought to address if intracellular NELL2 regulates PPE transcription in association with $\mathrm{Ca}^{2+}$-dependent intracellular signaling cascades. First, we used the drug A23187, a cation $\mathrm{Ca}^{2+}$ ionophore, to induce $\mathrm{Ca}^{2+}$ influx into the cytoplasm of cells $[34,35]$. As expected, NIH3T3 cells exposed to A23187 for $1 \mathrm{~h}$ showed a significant increase in PPELuc activity in the control group without the NELL2 expression vector (Figure 5A). 
Importantly, co-transfection of NELL2 expression vectors resulted in strong inhibition of the $\mathrm{Ca}^{2+}$ ionophore-induced increase in PPE-Luc activity, while this phenomenon was rescued partially with NELL2 $\triangle$ EGF-Ca ${ }^{2+}$ vectors. These results suggest that intracellular NELL2 affects PPE transcription, at least in part, by modulating $\mathrm{Ca}^{2+}$-dependent signaling.

In parallel, we also tested possible involvement of PKC signaling in NELL2-mediated regulation of PPE-Luc activity. To do this, NIH3T3 cells were treated with phorbol 12myristate 13-acetate (PMA), a PKC activating phorbol ester, for $3 \mathrm{~h}$ with or without NELL2 expression vectors (Figure 5B). As expected, PMA treatment stimulated PPE-Luc, while cotransfection of either NELL2 expression vectors or NELL2 expression vectors + BFA inhibited PMA-induced PPE-Luc activity. Given that NELL2 is known to be related to ERK activation $[15-18,36]$, one of the multiple downstream pathways of PKC signaling, we next examined the involvement of intracellular NELL2 in the activity of ERK, as represented by level of phosphorylated ERK (pERK). In western blot analyses, pERK was undetectable in control NIH3T3 cells, but was induced strongly by PMA treatment (Figure 5C). Consistently, the level of pERK was downregulated with transfection of NELL2 expression vectors, while it was rescued partially with vectors for NELL2 $\triangle \mathrm{EGF}^{-\mathrm{Ca}^{2+}}$. Therefore, intracellular NELL2 is likely linked with the $\mathrm{Ca}^{2+}$-PKC-ERK signaling pathway to regulate PPE transcription.

Previous studies have demonstrated that cFos is one of the final effectors of the PKCERK signaling pathways for regulation of gene expression [37-40]. Therefore, we examined intracellular NELL2-dependent cFos expression (Figure 5D). NIH3T3 cells treated with PMA showed significant induction of cFos proteins, while this induction was suppressed strongly with the NELL2 expression vectors. PMA-dependent cFos expression was recovered with NELL2 $\triangle \mathrm{EGF}-\mathrm{Ca}^{2+}$. Following these results, we examined NELL2 effects on cFos activation using the cFos promoter-luciferase reporter (cFos-Luc) vector [39]. The cFos-Luc was active transcriptionally over a wide range of concentrations in NIH3T3 cells (Figure 5E) and was 
decreased by transfection of the NELL2 expression vectors in a dose-dependent manner (Figure 5F). In Figure 5G, the patterns of cFos-Luc activity following expression vectors either for naïve NELL2 or NELL2 $\triangle \mathrm{EGF}-\mathrm{Ca}^{2+}$ were similar to those of the $\mathrm{Ca}^{2+}, \mathrm{PKC}$, and pERK experiments described above. Altogether, these results from in vitro approaches demonstrate the fundamental inhibitory role of intracellular NELL2 in PPE transcription, through sequential signaling cascades involving the $\mathrm{Ca}^{2+}$-PKC-ERK-cFos pathway.

Figure 5

A

B
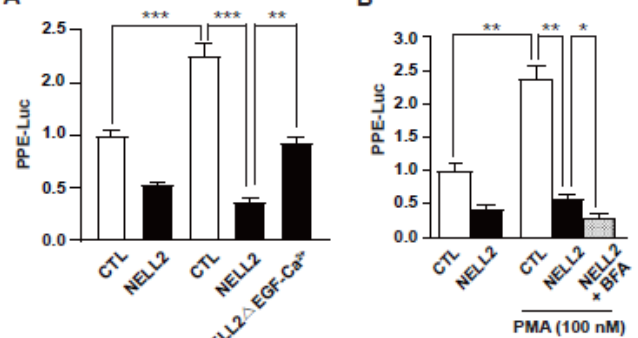

$\frac{3 v^{2}}{A 23187(5 \mu \mathrm{M})}$

$\mathrm{A}(100 \mathrm{nM})$
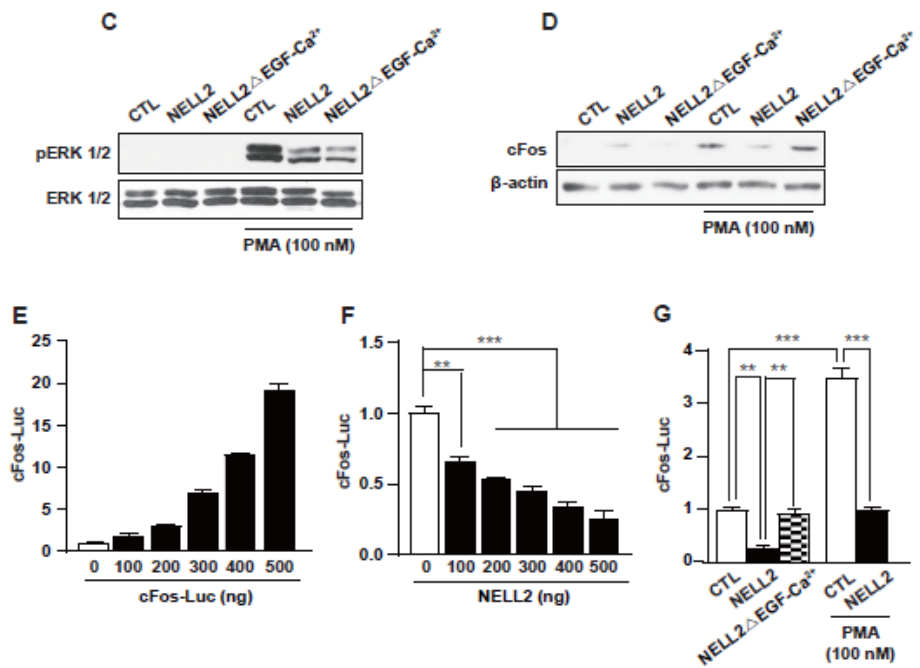

\subsection{Extracellular NELL2 activates PPE transcription}

As mentioned, NELL2 is a secretion protein and can modulate intracellular events of target cells through receptor signaling. Therefore, we sought to examine the effects of extracellular NELL2 on PPE transcription. In this case, synthetic NELL2 (sNELL2) was administered into the NIH3T3 cell culture medium. Application of sNELL2 resulted in a rapid increase in pERK (Figure 6A), which is in concert with our previous reports [16-18]. 
Subsequently, we revealed an activation role of extracellular sNELL2 on PPE-Luc activity (Figure 6B). These results demonstrate the dual-faceted actions of NELL2: while intracellular NELL2 inhibits the PKC-ERK pathway, extracellular NELL2 stimulates the same events to regulate PPE transcription.

\section{Figure 6}

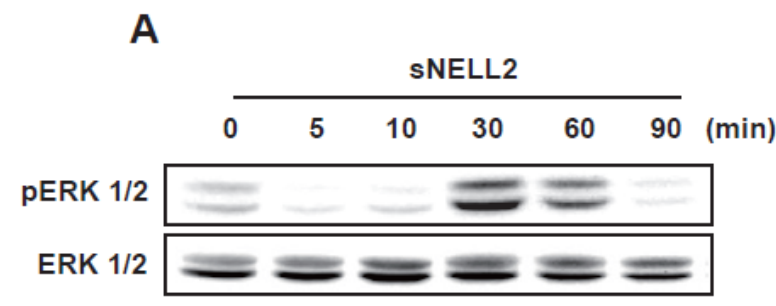

B

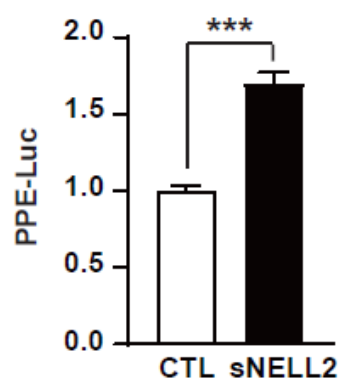

\subsection{In vivo inhibition of NELL2 synthesis increases PPE mRNA content in the brain}

Finally, we examined the effect of NELL2 on PPE gene expression in the brain by administration of NELL2-targeted antisense-oligodeoxynucleotide (AS-ODN) into the lateral ventricle of 2-month-old male rats. This strategy has been used to block the biosynthesis of NELL2 in the brain $[14,25,27]$. As shown in Figure 7A, NELL2 production in the AS-ODN group was significantly reduced compared to that of the group that received scrambledoligodeoxynucleotide (SCR-ODN) in the hypothalamus. In parallel, PPE mRNA level in the brain was elevated following NELL2 AS-ODN treatment (Figure 7B, C), suggesting inhibitory activity of NELL2 on PPE transcription in the brain. 


\section{Figure 7}
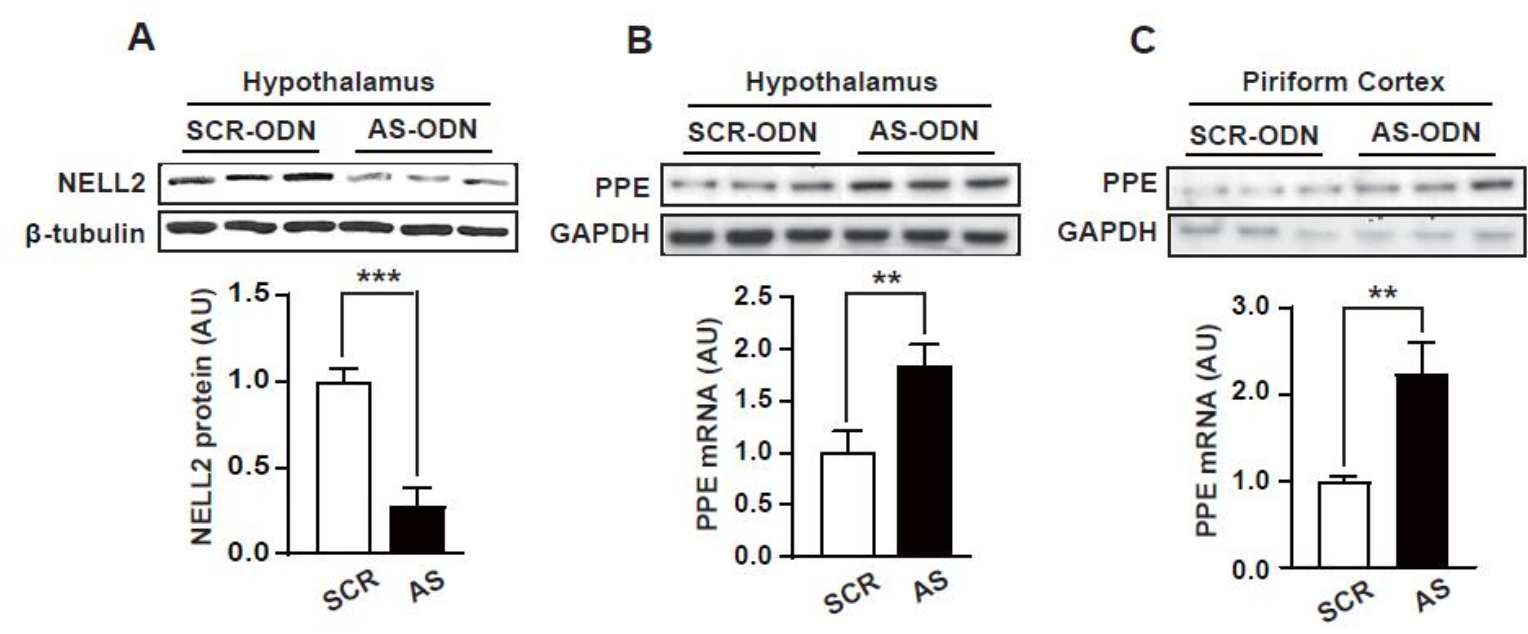

\section{Discussion}

In this study, we performed a combination of in vitro and in vivo experiments to determine the regulatory role of NELL2 in PPE gene expression. Our results showed that 1) hypothalamic neurons expressing PPE also expressed NELL2, suggesting its possible autocrine and/or paracrine action on PPE cells. 2) Intracellular NELL2 inhibited PPE gene transcription through suppression of the intracellular PKC-ERK signaling pathway. 3) Extracellular NELL2 stimulated PKC-ERK signaling and subsequently activated PPE transcription. 4) The in vivo disruption of NELL2 biosynthesis in the brain resulted in an increase in PPE mRNA levels. These results demonstrated for the first time that NELL2, a recently discovered neuromodulator and guide for axon-pathfinding, is involved in PPE gene transcription via two routes.

The most striking result in this study is that NELL2 is involved in a functionally opposing dual-faced mechanism in PPE gene transcription: while intracellular NELL2 inhibited $\mathrm{Ca}^{+}$-mediated and PKC-ERK-dependent signaling and suppressed PPE gene 
transcription, but this inhibitory action was reversed when NELL2 signaling was initiated extracellularly. In line with these observations, previous investigations have recognized dualfaceted NELL2 actions in axonal growth and synaptogenesis. For example, in our recent report, we showed that NELL2 has a key role in neurite and axonal growth as well as in the morphological development of neurons [41]. In an ex vivo experiment with primary embryonic cells, the cells developed rapid axonal growth when they were transfected with NELL2 overexpression vectors. Importantly, this phenomenon was mediated through Robo receptor 2/3-independent intracellular ERK signaling. On the other hand, other studies have demonstrated the chemorepellent action of extracellular NELL2 when coupled with Robo receptor signaling in axonal guidance [19-21]. These studies together indicate that NELL2 could be either an activator of axonal growth or an inhibitor of axonal pathfinding during neural development. The underlying mechanism that determines NELL2 fate is unclear. However, existing evidence suggests that it could depend on the site of NELL2 action initiation (e.g., intracellular vs. extracellular) or cell type-specific receptors for NELL2 (e.g., Robo2/3 vs. unknown). A recent study demonstrated the existence of different receptor and signaling systems for NELL2 action, such as testicular germ cell-derived NELL2 acts on male fertility by binding to orphan receptor tyrosine kinase-c-ros oncogene 1 (ROS1) [42]. In this study, we identified NELL2 expression in the PPE neurons of VMH but found no immunoreactive Robo2/3 in these PPE neurons (data not shown). Therefore, NELL2 might not exert its extracellular effect on PPE gene expression through Robo2/3 but through different unknown receptor(s) in the VMH. Further studies are required to uncover NELL2 receptor signaling in the hypothalamus.

Regarding NELL2 signaling, the important question is how the secretion factor NELL2 drives intracellular signaling cascades before being released from NELL2-producing cells. Secretory proteins, including NELL2, contain a signal peptide that enables release from the cells. However, we have reported the presence of a splice variant form of NELL2 that has a 
partially deleted signal peptide [43, 44]. Instead of being released, this NELL2 variant accumulates in the cytoplasm. Importantly, this cytosolic NELL2 was able to interact with PKC and negatively regulate PKC signaling [43], which resembles intracellular NELL2 actions in the current study. However, it is not likely that the intracellular NELL2 in this study mimics the actions of cytosolic NELL2, because cytosolic NELL2 is a product of the RNA-splice variant missing the functional signal peptide, while the intracellular NELL2 in this study contains an intact signal peptide and is processed through the ER-Golgi apparatus secretary pathway. The other possibility is that NELL2 exerts an effect on intracellular signaling at the ER before being released. Secreting proteins visit the ER during the conventional release process. We previously designed a reporter vector to visualize intracellular localization of NELL2 (NELL2-EGFP) and observed that NELL2 travels through the ER and Golgi apparatus [45]. This result suggests that NELL2 follows the conventional release pathway. Keeping this in mind, we considered that NELL2 might have prolonged residence in the ER, induced by BFA (NELL2/BFA), an inhibitor of ER-Golgi transfer [33], or using a NELL2 expression vector fused with the ER retention signal KDEL (NELL2-KDEL) [31, 32]. Under these circumstances, PPE gene transcription was inhibited at a similar level to that of the intracellular naïve NELL2. This observation suggests that the ER and not the cytosol could be the site where intracellular NELL2 initiates PKC-ERK signaling for regulation of PPE gene expression.

In the CNS, multiple factors, including sex hormones [46, 47], nutrients [48], and neurotransmitters [49], participate in the regulation of PPE synthesis. Within PPE cells, investigations identified a key role for intracellular cAMP- and PKC-dependent pathways for PPE transcription [9]. Here, we provide evidence that NELL2 is a novel player regulating PPE transcription. As already mentioned, NELL2 possesses several functional domains. Among these domains, six EGF-like repeat domains have been identified as key domains for interaction with PKC [10]. In line with this, our results show that NELL2, through its EGF- 
like repeat domains, modulates the $\mathrm{Ca}^{2+}$-dependent PKC-ERK-cFos pathway to regulate PPE transcription. In consideration of this, we investigated the effects of mutant NELL2 lacking $\mathrm{Ca}^{2+}$-binding EGF domains on PKC-ERK signaling in PPE gene regulation. Interestingly, mutant NELL2 partially lost the inhibitory nature of the naïve NELL2 on PPE-Luc activity, pERK, and cFos expression. Together, these results indicate that the $\mathrm{Ca}^{2+}$-binding EGF domains are required to achieve the inhibitory NELL2 effect on $\mathrm{Ca}^{2+}$-dependent PKC-ERK signaling for PPE expression and suggest that NELL2 function in the ER is related to intracellular $\mathrm{Ca}^{2+}$. Further studies are necessary to clarify how NELL2 initiates $\mathrm{Ca}^{2+}$ dependent PKC activation in the ER.

In summary, the present findings identify NELL2 as a novel component involved in regulation of PPE gene transcription through the $\mathrm{Ca}^{2+}$-dependent PKC-ERK-cFos pathway. Furthermore, the direction of NELL2 actions on PPE gene transcription is spatio-dependent.

\section{Materials and Methods}

\subsection{Double In Situ hybridization}

Two-month-old male Sprague-Dawley rats and C57BL/6 mice (Hyochang Science, Daegu, Korea) were used for histochemical analyses (permission number from Animal Care and Use Committee at the University of Ulsan: BJL-21-010). To identify NELL2 expression in the cells expressing PPE, brains of 2-month-old male rats were fixed by transcardiac perfusion of $4 \%$ paraformaldehyde-borate buffer, $\mathrm{pH} 9.5$. Thereafter, the brains were postfixed for $\sim 20 \mathrm{~h}$ at $4^{\circ} \mathrm{C}$ in the same fixative containing $10 \%$ sucrose, blocked coronally, frozen on dry ice, and stored at $-80^{\circ} \mathrm{C}$ until use. Sections $(30 \mu \mathrm{m})$ were prepared with a freezing sliding microtome and processed for hybridization as reported previously [50].

Hybridization was performed as recommended [50] with minor modifications. The probe was prepared by SP6 RNA polymerase-directed in vitro transcription with a 333-bp 
NELL2 cDNA template obtained by PCR amplification of the coding region corresponding to nucleotides 548-880 in rat NELL2 mRNA (NCBI GenBank Accession number: AY089719). The 252-bp PPE cDNA template was obtained from nucleotides 472-723 in rat PPE mRNA (NCBI GenBank Accession number: Y07503). For double-labeled in situ hybridization, we used an ${ }^{35}$ S-UTP-labeled NELL2 cRNA probe and a digoxygenin-UTP-labeled PPE cRNA probe. Following overnight hybridization at $55-56^{\circ} \mathrm{C}$, the slides were washed and processed for digoxygenin detection as reported [14]. After dehydration, the slides were dipped in Ilford K5 emulsion (without defatting) for isotopic hybridization and exposed to the emulsion for 3 weeks at $4^{\circ} \mathrm{C}$. At this time, the slides were developed, quickly dehydrated, dried, and coverslipped for microscopic examination.

\subsection{Immunohistochemistry (IHC)}

Immunohistochemistry procedures in this study followed the descriptions in our previous reports $[22,23,25,51]$. Briefly, the brains of mice were collected following $4 \%$ paraformaldehyde perfusion and stored at $-80^{\circ} \mathrm{C}$ until use. Coronal cryostat sections of 10 $\mu \mathrm{m}$ thickness were air-dried and incubated for $30 \mathrm{~min}$ in phosphate-buffered saline (PBS) and for $1 \mathrm{~h}$ in blocking buffer (3\% BSA, 0.3\% Triton X-100 in PBS) at room temperature (RT). The brain sections were incubated overnight at $-4^{\circ} \mathrm{C}$ with rabbit anti-rat NELL2 antibodies $[22,25]$ diluted in blocking buffer (1:500). After 3x10-min washes with slow agitation in PBS, the sections were incubated for $2 \mathrm{~h}$ at RT with secondary antibodies (goat anti-rabbit IgG with Alexa Fluor-594: 1:1000, \#ab150084, Abcam, Cambridge, MA, USA). The sections were incubated for $1 \mathrm{~h}$ in blocking buffer at RT and incubated overnight at $-4^{\circ} \mathrm{C}$ with primary antibody against PPE diluted in blocking buffer (goat anti-PPE: NBP1-20963, 1:500, Novus Biologicals, Centennial, CO, USA). The sections were washed $3 \times 10-$ min in PBS and incubated with secondary antibodies (donkey anti-goat IgG with Alexa Fluor-488: \#ab150129, 1:1000, Abcam) for $2 \mathrm{~h}$ at RT. Following the series of washing steps, the sections were cover- 
slipped and subjected to fluorescence microscopy (Axioplan2 Imaging; Carl Zeiss Microimaging Inc., Thornwood, NY, USA).

\subsection{Plasmids and Mutant NELL2 Constructs}

Transcriptional activity assays were carried out using 5'-flanking sequences of genes cloned into luciferase reporter plasmids. For the PPE gene, we subcloned a 2.7-kb HincII DNA fragment containing nucleotides (nt) -2495 to +207 of the human PPE gene (kindly provided by Dr. L. Kobierski, Harvard Medical School, MA, USA) into pGL2-basic luciferase reporter vector (PPE-Luc). For cFos, we used a construct (a gift from Dr. R. Prywes, Columbia University, NY, USA) containing nt -711 to +45 of human cFos promoter constructed in the luciferase reporter vector (cFos-Luc). Previously, we reported cloning of rat NELL2 cDNA [27]. NELL2 contains several functional domains: signal peptide, thrombospondin-1 (TSP-N)-like module, five von Willebrand factor C (CR) domains, and six EGF-like domains [10]. Using overlapping PCR, we prepared several mutant cDNAs encoding proteins lacking functional domains [16]: NELL2 $\triangle$ TSP-N (lacking TSP-N domain); NELL2 $\triangle$ TSP-N-CR (lacking TSP-N and 2 C-terminal CR domains); NELL2 $\triangle$ EGF-Ca ${ }^{2+}$ (lacking three EGF-like $\mathrm{Ca}^{2+}$-binding domains); and NELL2 $\triangle \mathrm{EGF}$ (lacking all 6 EGF-like domains). The mutants were cloned into the expression vector pcDNA 3.1-Zeo ${ }^{+}$ (Invitrogen Life Technologies, Carlsbad, CA, USA) and confirmed by automatic sequencing.

\subsection{Cell Culture and Assays for Luciferase Activities}

Mouse embryonic fibroblast NIH3T3 cells were grown in Dulbecco's modified Eagle's medium (H-DMEM) containing high glucose and $10 \%$ bovine calf serum at $37^{\circ} \mathrm{C}$ in a humidified atmosphere with $5 \% \mathrm{CO}_{2}$. To determine whether intracellular NELL2 regulates PPE transcription, NIH3T3 cells were transfected transiently with PPE-Luc and expression 
vectors containing naïve or mutant NELL2 coding region using Lipofectamine/Plus reagents (Invitrogen, Carlsbad, CA, USA). NELL2-KDEL carrying the carboxy-terminal ER retention sequence KDEL $[31,32]$ was kindly provided by Dr. EM Hwang (Center for Functional Connectomics, Korea Institute of Science and Technology (KIST), Seoul, Korea). To chemically retain NELL2 in the ER, BFA (Sigma-Aldrich, St. Louis, MO, USA), an inhibitor of ER-Golgi trafficking [33], was added to the culture medium of cells transfected with NELL2 expression vectors. To determine the effect of NELL2 on $\mathrm{Ca}^{2+}$-dependent and PKCinduced PPE transcription, phosphorylation of ERK (pERK), and cFos expression, the NIH3T3 cells transfected with NELL2 expression vectors were treated with phorbol 12myristate 13-acetate (PMA, \#524400, Calbiochem, La Jolla, CA, USA) or with $\mathrm{Ca}^{2+}$ ionophore A23187 (\#100105, Calbiochem). To further identify the effect of extracellularly released NELL2 on PPE-Luc and pERK, the cells were treated with synthetic human NELL2 protein (\#13132-H08B, Sino Biological Inc., Wayne, PA, USA). Luciferase assays were performed using a luciferase reporter assay kit (Promega, Madison, WI, USA). Transfection efficiency was normalized by co-transfecting the $\beta$-galactosidase reporter plasmid (pCMV- $\beta$ gal, Clontech, Palo Alto, CA, USA) at $60 \mathrm{ng} /$ well.

\subsection{Blockade of NELL2 Synthesis}

To examine the effect of NELL2 synthesis blockade on PPE mRNA contents in the rat brain, a phosphorothioate antisense-oligodeoxynucleotide (AS-ODN) (Genotech Corp., Daejeon, Korea) was delivered into the lateral ventricle of 2-month-old male rats. The ASODN used (5'-CCG GGA TTC CAT GGC GTG CAT-3') is complementary to a 21-nt sequence encompassing the NELL2 translation initiation site [26, 27]. As a control, scrambled (SCR) sequence of AS-ODN was used: 5'-TAT CGC ATG CGG GCC TAT GCG-3'. For injection, the ODNs were diluted to a final concentration of $0.5 \mathrm{nmol} / \mu \mathrm{l}$ in artificial cerebrospinal fluid (ACSF). A polyethylene cannula (outer diameter, $1.05 \mathrm{~mm}$; inner diameter, 
$0.35 \mathrm{~mm}$ ) was implanted stereotaxically into the lateral ventricle (coordinates: $\mathrm{AP}=1.0 \mathrm{~mm}$ caudal to bregma; $\mathrm{V}=3.6 \mathrm{~mm}$ from the dura mater; $\mathrm{L}=0.16 \mathrm{~mm}$ from the midline). After one week of recovery, ODNs were injected through the cannula. To determine effects, ASODN ( 2 nmol in $4 \mu \mathrm{l}$ ACSF/rat) was injected with a Hamilton syringe once a day for 2 days. The rats were killed $24 \mathrm{~h}$ after the second ODN injection, and tissues (hypothalamus and basal cortical regions surrounding the piriform cortex) were collected for western blot analysis of NELL2 protein and northern blot analysis of PPE mRNA.

\subsection{Northern blot hybridization}

To determine the effect of NELL2 synthesis blockade on PPE mRNA content, we performed northern blot hybridization using hypothalamus and piriform cortex injected with NELL2 AS-ODN. Total RNA was prepared using the acid guanidium thiocyanate-phenolchloroform method [52], and a $20 \mu \mathrm{g}$ sample of total RNA was separated by electrophoresis in a $1.2 \%$ formaldehyde-agarose gel containing ethidium bromide. Following transfer to a nylon membrane for $18 \mathrm{~h}$ by diffusion blotting, the membrane was dried and cross-linked by UV illumination. The $\left[{ }^{32} \mathrm{P}\right] \mathrm{dCTP}$-labeled PPE cDNA probe was prepared using the random primer-labeling method $[24,53]$. The labeled probe was separated from unincorporated $\left[{ }^{32} \mathrm{P}\right] \mathrm{dCTP}$ by a Nick column (Amersham-Pharmacia Biotech, Little Chalfort, UK). Prehybridization was carried out at $42^{\circ} \mathrm{C}$ for $2 \mathrm{~h}$ in a heat-sealed plastic bag with a hybridization buffer. After addition of the ${ }^{32} \mathrm{P}$-labeled cDNA probe, hybridization was performed at $42^{\circ} \mathrm{C}$ for $20 \mathrm{~h}$. The membrane was washed twice with $2 \times$ SSC and $0.1 \%$ SDS at RT for $20 \mathrm{~min}$, followed by a second wash with $0.1 \times$ SSC, $0.5 \%$ SDS, and 5 mM EDTA (pH $8.0)$ at $50^{\circ} \mathrm{C}$ for $5 \mathrm{~min}$. The membrane was dried and exposed to X-ray film at $-70^{\circ} \mathrm{C}$ for $2-4$ days.

\subsection{Real-time PCR}


To determine the effect of NELL2 on endogenous PPE expression, RNA ( $2 \mu \mathrm{g})$ was isolated from NIH3T3 cells transfected with control vector or NELL2 expression vector. Total RNA samples were extracted using the Sensi-TriJol ${ }^{\text {TM }}$ reagent (\#LGR-1117, Lugen Sci Co., Bucheon, Korea) according to the manufacturer's instructions. cDNA was synthesized using MMLV reverse transcriptase (\#3201, Beams Bio., Seongnam, Korea). After reverse transcription, real-time PCR analyses were performed with Bright-Green $2 \times$ qPCR MasterMix-ROX (ABM, Vancouver, Canada) using a StepOnePlus Real-Time PCR System (Applied Biosystems, Thermo Fisher Scientific, Waltham, MA, USA) for $\sim 40$ cycles. The target DNA species were amplified by real-time PCR using the following primer sets: PPE sense primer, 5'-CGA CAT CAA TTT CCT GGC GT-3'; PPE antisense primer, 5'-AGA TCC TTG CAG GTC TCC CA-3'; $\beta$-actin sense primer, 5'-TGG AAT CCT GTG GCA TCC ATG AAA C-3'; $\beta$-actin antisense primer, 5'-TAA AAC GCA GCT CAG TAA CAG TCC G -3'. Data were normalized for gene expression using $\beta$-actin as an internal control. The expression pattern of $\beta$-actin in our experimental sets did not differ between groups. The $2^{-\triangle \triangle \mathrm{CT}}$ method [54] was used to analyze the relative quantification of gene expression.

\subsection{Western blot analysis}

NIH3T3 cells and hypothalamic fragments were homogenized with lysis buffer (Mammalian cell protein extract reagent (M-PER), \# 78501; Tissue protein extraction reagent (T-PER), \#78510, Pierce Chemical Co., Rockford, IL, USA) containing protease inhibitor cocktail (Roche, Rotkreuz, Switzerland). Briefly, protein concentration was measured by the Bradford assay (\#5000006, Bio-Rad, Hercules, CA, USA), and $20 \mu \mathrm{g}$ of proteins from each sample were separated by SDS-PAGE and transferred onto PVDF membranes by electrophoretic transfer. The membrane was blocked with 5\% non-fat skim milk in TBSTween and incubated with antibodies against NELL2 (1:1000, \#sc-390137, Santa Cruz 
Biotech., Santa Cruz, CA, USA), pERK (1:1000, \#9101, CELL Signaling Technology, Beverly, MA, USA), ERK (1:1000, \#sc-153, Santa Cruz Biotech.), or cFos (1:1000, \#sc-7202, Santa Cruz Biotech.). The membrane was incubated with HRP-conjugated mouse secondary antibody (1:3000, \#7076, Cell Signaling) or HRP-conjugated rabbit secondary antibody (1:3000, \#7074, Cell Signaling), and the immunoreactive signals were detected by chemiluminescent detection reagent (\#34095, Thermo Scientific). Protein density was normalized using $\beta$-tubulin (1:3000, \#sc-5274, Santa Cruz Biotech.) or $\beta$-actin (1:4000, \#A5441, Sigma-Aldrich), and Image J software was used to analyze data.

\subsection{Statistical analyses}

Statistical analyses were performed in GraphPad Prism 9 software (GraphPad Software, San Diego, CA, USA). All data are expressed as the mean \pm SEM. Student's $t$ test was used to compare the two groups.

Author Contributions: HRK, CMH, JWP, JKJ, and BJL conceived and designed the research; HRK, DHK, CMH, JC, SRO, and JKJ performed experiments; HRK, DHK, CMH, JC, SRO, JKJ, and BJL analyzed data; HRK, CMH, SRO, JKJ, and BJL wrote the manuscript. All authors contributed to overall data interpretation, provided intellectual input, and approved the final manuscript. All authors have read and agreed to the published version of the manuscript.

Funding: This research was supported by the Priority Research Centers Program (2014R1A6A1030318) and the Korea Health Technology R\&D Project through the Korea Health Industry Development Institute (KHIDI), funded by the Ministry of Health and Welfare, South Korea (H I14C1135). 
Abbreviations: NELL2, neural epidermal growth factor (EGF)-like-like 2; enkephalin (ENK); PPE, preproenkephalin; EGF, epidermal growth factor; PKC, protein kinase C; ERK, extracellular signal-regulated kinase; VMH, ventromedial hypothalamic nucleus; Luc, luciferase; BFA: brefeldin A 


\section{References}

1. Duque-Diaz, E.; Alvarez-Ojeda, O.; Covenas, R., Enkephalins and ACTH in the mammalian nervous system. Vitam Horm 2019, 111, 147-193.

2. Bodnar, R. J., Endogenous Opiates and Behavior: 2015. Peptides 2017, 88, 126-188.

3. Henry, M. S.; Gendron, L.; Tremblay, M. E.; Drolet, G., Enkephalins: Endogenous Analgesics with an Emerging Role in Stress Resilience. Neural Plast 2017, 2017, 1546125.

4. Noda, M.; Teranishi, Y.; Takahashi, H.; Toyosato, M.; Notake, M.; Nakanishi, S.; Numa, S., Isolation and structural organization of the human preproenkephalin gene. Nature 1982, 297, (5865), 431-4.

5. Koshimizu, Y.; Wu, S. X.; Unzai, T.; Hioki, H.; Sonomura, T.; Nakamura, K. C.; Fujiyama, F.; Kaneko, T., Paucity of enkephalin production in neostriatal striosomal neurons: analysis with preproenkephalin-green fluorescent protein transgenic mice. Eur J Neurosci 2008, 28, (10), 2053-64.

6. Morissette, M.; Le Saux, M.; D'Astous, M.; Jourdain, S.; Al Sweidi, S.; Morin, N.; Estrada-Camarena, E.; Mendez, P.; Garcia-Segura, L. M.; Di Paolo, T., Contribution of estrogen receptors alpha and beta to the effects of estradiol in the brain. J Steroid Biochem Mol Biol 2008, 108, (3-5), 327-38.

7. Quinones-Jenab, V.; Ogawa, S.; Jenab, S.; Pfaff, D. W., Estrogen regulation of preproenkephalin messenger RNA in the forebrain of female mice. J Chem Neuroanat 1996, 12, (1), 29-36.

8. Dellovade, T. L.; Kia, H. K.; Zhu, Y. S.; Pfaff, D. W., Thyroid hormone coadministration inhibits the estrogen-stimulated elevation of preproenkephalin mRNA in female rat hypothalamic neurons. Neuroendocrinology 1999, 70, (3), 16874. 
9. Borsook, D.; Hyman, S. E., Proenkephalin gene regulation in the neuroendocrine hypothalamus: a model of gene regulation in the CNS. Am J Physiol 1995, 269, (3 Pt 1), E393-408.

10. Kuroda, S.; Tanizawa, K., Involvement of epidermal growth factor-like domain of NELL proteins in the novel protein-protein interaction with protein kinase C. Biochem Biophys Res Commun 1999, 265, (3), 752-7.

11. Handford, P. A.; Mayhew, M.; Baron, M.; Winship, P. R.; Campbell, I. D.; Brownlee, G. G., Key residues involved in calcium-binding motifs in EGF-like domains. Nature 1991, 351, (6322), 164-7.

12. Rao, Z.; Handford, P.; Mayhew, M.; Knott, V.; Brownlee, G. G.; Stuart, D., The structure of a $\mathrm{Ca}(2+)$-binding epidermal growth factor-like domain: its role in proteinprotein interactions. Cell 1995, 82, (1), 131-41.

13. Nelson, B. R.; Claes, K.; Todd, V.; Chaverra, M.; Lefcort, F., NELL2 promotes motor and sensory neuron differentiation and stimulates mitogenesis in DRG in vivo. Dev Biol 2004, 270, (2), 322-35.

14. Ha, C. M.; Choi, J.; Choi, E. J.; Costa, M. E.; Lee, B. J.; Ojeda, S. R., NELL2, a neuron-specific EGF-like protein, is selectively expressed in glutamatergic neurons and contributes to the glutamatergic control of $\mathrm{GnRH}$ neurons at puberty. Neuroendocrinology 2008, 88, (3), 199-211.

15. Aihara, K.; Kuroda, S.; Kanayama, N.; Matsuyama, S.; Tanizawa, K.; Horie, M., A neuron-specific EGF family protein, NELL2, promotes survival of neurons through mitogen-activated protein kinases. Brain Res Mol Brain Res 2003, 116, (1-2), 86-93.

16. Choi, E. J.; Kim, D. H.; Kim, J. G.; Kim, D. Y.; Kim, J. D.; Seol, O. J.; Jeong, C. S.; Park, J. W.; Choi, M. Y.; Kang, S. G.; Costa, M. E.; Ojeda, S. R.; Lee, B. J., Estrogendependent transcription of the NEL-like 2 (NELL2) gene and its role in protection from cell death. J Biol Chem 2010, 285, (32), 25074-84. 
17. Kim, D. H.; Kim, H. R.; Choi, E. J.; Kim, D. Y.; Kim, K. K.; Kim, B. S.; Park, J. W.; Lee, B. J., Neural epidermal growth factor-like like protein 2 (NELL2) promotes aggregation of embryonic carcinoma P19 cells by inducing N-cadherin expression. PLoS One 2014, 9, (1), e85898.

18. Kim, D. Y.; Kim, H. R.; Kim, K. K.; Park, J. W.; Lee, B. J., NELL2 function in the protection of cells against endoplasmic reticulum stress. Mol Cells 2015, 38, (2), 14550.

19. Pak, J. S.; DeLoughery, Z. J.; Wang, J.; Acharya, N.; Park, Y.; Jaworski, A.; Ozkan, E., NELL2-Robo3 complex structure reveals mechanisms of receptor activation for axon guidance. Nat Commun 2020, 11, (1), 1489.

20. Jaworski, A.; Tom, I.; Tong, R. K.; Gildea, H. K.; Koch, A. W.; Gonzalez, L. C.; Tessier-Lavigne, M., Operational redundancy in axon guidance through the multifunctional receptor Robo3 and its ligand NELL2. Science 2015, 350, (6263), 961-5.

21. Yamamoto, N.; Kashiwagi, M.; Ishihara, M.; Kojima, T.; Maturana, A. D.; Kuroda, S.; Niimi, T., Robo2 contains a cryptic binding site for neural EGFL-like (NELL) protein 1/2. J Biol Chem 2019, 294, (12), 4693-4703.

22. Jeong, J. K.; Kim, H. R.; Hwang, S. M.; Park, J. W.; Lee, B. J., Region- and neuronal phenotype-specific expression of NELL2 in the adult rat brain. Mol Cells 2008a, 26, (2), 186-92.

23. Jeong, J. K.; Kim, J. G.; Kim, H. R.; Lee, T. H.; Park, J. W.; Lee, B. J., A Role of Central NELL2 in the Regulation of Feeding Behavior in Rats. Mol Cells 2017, 40, (3), 186-194.

24. Choi, E. J.; Ha, C. M.; Choi, J.; Kang, S. S.; Choi, W. S.; Park, S. K.; Kim, K.; Lee, B. J., Low-density cDNA array-coupled to PCR differential display identifies new estrogen-responsive genes during the postnatal differentiation of the rat hypothalamus. 
Brain Res Mol Brain Res 2001, 97, (2), 115-28.

25. Jeong, J. K.; Ryu, B. J.; Choi, J.; Kim, D. H.; Choi, E. J.; Park, J. W.; Park, J. J.; Lee, B. J., NELL2 participates in formation of the sexually dimorphic nucleus of the preoptic area in rats. J Neurochem 2008b, 106, (4), 1604-13.

26. Ryu, B. J.; Kim, H. R.; Jeong, J. K.; Lee, B. J., Regulation of the female rat estrous cycle by a neural cell-specific epidermal growth factor-like repeat domain containing protein, NELL2. Mol Cells 2011, 32, (2), 203-7.

27. Kim, H.; Ha, C. M.; Choi, J.; Choi, E. J.; Jeon, J.; Kim, C.; Park, S. K.; Kang, S. S.; Kim, K.; Lee, B. J., Ontogeny and the possible function of a novel epidermal growth factor-like repeat domain-containing protein, NELL2, in the rat brain. $J$ Neurochem 2002, 83, (6), 1389-400.

28. Harlan, R. E.; Shivers, B. D.; Romano, G. J.; Howells, R. D.; Pfaff, D. W., Localization of preproenkephalin mRNA in the rat brain and spinal cord by in situ hybridization. J Comp Neurol 1987, 258, (2), 159-84.

29. Khachaturian, H.; Alessi, N. E.; Munfakh, N.; Watson, S. J., Ontogeny of opioid and related peptides in the rat cns and pituitary: an immunocytochemical study. Life Sci 1983, 33 Suppl 1, 61-4.

30. Takahashi, K.; Fujita, T.; Takeuchi, T., Production of bioactive enkephalin from the nonendocrine cell lines COS-7, NIH3T3, Ltk-, and C2C12. Peptides 1995, 16, (5), 933-8.

31. Munro, S.; Pelham, H. R., A C-terminal signal prevents secretion of luminal ER proteins. Cell 1987, 48, (5), 899-907.

32. Mei, M.; Zhai, C.; Li, X.; Zhou, Y.; Peng, W.; Ma, L.; Wang, Q.; Iverson, B. L.; Zhang, G.; Yi, L., Characterization of aromatic residue-controlled protein retention in the endoplasmic reticulum of Saccharomyces cerevisiae. J Biol Chem 2017, 292, (50), 20707-20719. 
33. Chardin, P.; McCormick, F., Brefeldin A: the advantage of being uncompetitive. Cell 1999, 97, (2), 153-5.

34. Davies, E. V.; Hallett, M. B., Near membrane Ca2+ changes resulting from store release in neutrophils: detection by FFP-18. Cell Calcium 1996, 19, (4), 355-62.

35. Lages, B.; Weiss, H. J., Original Article: Comparison of A23187 vs Ionomycininduced Responses and Cytosolic Calcium Increases in Aequorin-loaded Human Platelets. Evidence for Ionophore-specific Differences in Intracellular Calcium Release. Platelets 1995, 6, (6), 359-65.

36. Liu, J.; Liu, D.; Zhang, X.; Li, Y.; Fu, X.; He, W.; Li, M.; Chen, P.; Zeng, G.; DiSanto, M. E.; Wang, X.; Zhang, X., NELL2 modulates cell proliferation and apoptosis via ERK pathway in the development of benign prostatic hyperplasia. Clin Sci (Lond) 2021, 135, (13), 1591-1608.

37. Sgambato, V.; Pages, C.; Rogard, M.; Besson, M. J.; Caboche, J., Extracellular signalregulated kinase (ERK) controls immediate early gene induction on corticostriatal stimulation. J Neurosci 1998, 18, (21), 8814-25.

38. Nakakuki, T.; Birtwistle, M. R.; Saeki, Y.; Yumoto, N.; Ide, K.; Nagashima, T.; Brusch, L.; Ogunnaike, B. A.; Okada-Hatakeyama, M.; Kholodenko, B. N., Ligand-specific cFos expression emerges from the spatiotemporal control of ErbB network dynamics. Cell 2010, 141, (5), 884-96.

39. Oh, D. Y.; Wang, L.; Ahn, R. S.; Park, J. Y.; Seong, J. Y.; Kwon, H. B., Differential G protein coupling preference of mammalian and nonmammalian gonadotropinreleasing hormone receptors. Mol Cell Endocrinol 2003, 205, (1-2), 89-98.

40. Kominato, Y.; Tachibana, T.; Dai, Y.; Tsujino, H.; Maruo, S.; Noguchi, K., Changes in phosphorylation of ERK and Fos expression in dorsal horn neurons following noxious stimulation in a rat model of neuritis of the nerve root. Brain Res 2003, 967, (1-2), 8997. 
41. Kim, H. R.; Kim, D. H.; An, J. Y.; Kang, D.; Park, J. W.; Hwang, E. M.; Seo, E. J.; Jang, I. H.; Ha, C. M.; Lee, B. J., NELL2 Function in Axon Development of Hippocampal Neurons. Mol Cells 2020, 43, (6), 581-589.

42. Kiyozumi, D.; Noda, T.; Yamaguchi, R.; Tobita, T.; Matsumura, T.; Shimada, K.; Kodani, M.; Kohda, T.; Fujihara, Y.; Ozawa, M.; Yu, Z.; Miklossy, G.; Bohren, K. M.; Horie, M.; Okabe, M.; Matzuk, M. M.; Ikawa, M., NELL2-mediated lumicrine signaling through OVCH2 is required for male fertility. Science 2020, 368, (6495), 1132-1135.

43. Lee da, Y.; Kim, E.; Lee, Y. S.; Ryu, H.; Park, J. Y.; Hwang, E. M., The cytosolic splicing variant of NELL2 inhibits PKCbeta1 in glial cells. Biochem Biophys Res Commun 2014, 454, (3), 459-64.

44. Hwang, E. M.; Kim, D. G.; Lee, B. J.; Choi, J.; Kim, E.; Park, N.; Kang, D.; Han, J.; Choi, W. S.; Hong, S. G.; Park, J. Y., Alternative splicing generates a novel nonsecretable cytosolic isoform of NELL2. Biochem Biophys Res Commun 2007, 353, (3), 805-11.

45. Ha, C. M.; Hwang, E. M.; Kim, E.; Lee, D. Y.; Chang, S.; Lee, B. J.; Hong, S. G.; Park, J. Y., The molecular mechanism of NELL2 movement and secretion in hippocampal progenitor HiB5 cells. Mol Cells 2013, 36, (6), 527-33.

46. Spool, J. A.; Stevenson, S. A.; Angyal, C. S.; Riters, L. V., Contributions of testosterone and territory ownership to sexually-motivated behaviors and mRNA expression in the medial preoptic area of male European starlings. Horm Behav 2016, 86, 36-44.

47. Le Saux, M.; Di Paolo, T., Chronic estrogenic drug treatment increases preproenkephalin mRNA levels in the rat striatum and nucleus accumbens. Psychoneuroendocrinology 2005, 30, (3), 251-60.

48. Hawkins, P.; Hanson, M. A.; Matthews, S. G., Maternal undernutrition in early 
gestation alters molecular regulation of the hypothalamic-pituitary-adrenal axis in the ovine fetus. J Neuroendocrinol 2001, 13, (10), 855-61.

49. Morin, N.; Morissette, M.; Gregoire, L.; Di Paolo, T., mGlu5, Dopamine D2 and Adenosine A2A Receptors in L-DOPA-induced Dyskinesias. Curr Neuropharmacol 2016, 14, (5), 481-93.

50. Berg-von der Emde, K.; Dees, W. L.; Hiney, J. K.; Hill, D. F.; Dissen, G. A.; Costa, M. E.; Moholt-Siebert, M.; Ojeda, S. R., Neurotrophins and the neuroendocrine brain: different neurotrophins sustain anatomically and functionally segregated subsets of hypothalamic dopaminergic neurons. J Neurosci 1995, 15, (6), 4223-37.

51. Kim, D. H.; Kim, K. K.; Lee, T. H.; Eom, H.; Kim, J. W.; Park, J. W.; Jeong, J. K.; Lee, B. J., Transcription Factor TonEBP Stimulates Hyperosmolality-Dependent Arginine Vasopressin Gene Expression in the Mouse Hypothalamus. Front Endocrinol (Lausanne) 2021, 12, 627343.

52. Chomczynski, P.; Sacchi, N., Single-step method of RNA isolation by acid guanidinium thiocyanate-phenol-chloroform extraction. Anal Biochem 1987, 162, (1), $156-9$.

53. Feinberg, A. P.; Vogelstein, B., A technique for radiolabeling DNA restriction endonuclease fragments to high specific activity. Anal Biochem 1983, 132, (1), 6-13.

54. Livak, K. J.; Schmittgen, T. D., Analysis of relative gene expression data using realtime quantitative PCR and the 2(-Delta Delta C(T)) Method. Methods 2001, 25, (4), 402-8.

\section{Figure Legends}

Figure 1. Localization of NELL2 expression in neurons expressing preproenkephalin (PPE). To identify NELL2 expression in PPE-positive neurons, we performed double in situ 
hybridization using digoxygenin-labeled (Dig) cRNA probe for PPE and ${ }^{35}$ S-UTP-labeled (35S) cRNA probe for NELL2. PPE mRNA expression was found in the lateral ventromedial hypothalamic nucleus (LVMH) (A), caudate putamen (CP), lateral nucleus of the amygdala (LNA) (B), and the piriform cortex (PirC) (C). Silver grains for NELL2 mRNA were found and merged with PPE mRNA signals in LVMH, LNA, and Pir C. Scale bars $=10 \mu \mathrm{m}$ (A and C) and $20 \mu \mathrm{m}(\mathrm{B})$.

Figure 2. NELL2 expression in the enkephalinergic cells of the brain. Double immunohistochemistry was applied to coronal brain sections of mice to identify immunoreactive NELL2 proteins (red) in the cells expressing PPE (green). (A) Images shown are of the lateral ventromedial hypothalamic nucleus $(\mathrm{LVMH})$ of mouse brain. Scale bar $=$ $100 \mu \mathrm{m}$. (B) Higher-magnification images from the inset area shown in A. Scale bar $=50 \mu \mathrm{m}$.

Figure 3. Effect of intracellular NELL2 on PPE transcription. (A-D) Luciferase (Luc) reporter vector (pGL2) containing the 5'-flanking region of the PPE gene (PPE-Luc) was transfected into NIH3T3 cells with an expression vector carrying the NELL2-coding region (NELL2) at the concentrations indicated. The cells were harvested for Luc and $\beta$ galactosidase assays at $24 \mathrm{~h}$ after transfection, and relative Luc activity is shown. (A) A doserelated increase in PPE-Luc activity following transfection of different concentrations of PPE-Luc vectors. (B) Dose-related decrease of PPE-Luc activity by transfected NELL2 expression vector (NELL2). (C) Decrease of PPE-Luc activity by expression vector carrying a NELL2-coding region fused with an ER retention signal at its C-terminal end (NELL2KDEL). (D) Effect of brefeldin A (BFA), an inhibitor of transport from ER to Golgi apparatus, on PPE-Luc activity in cells transfected with the indicated amount of NELL2 expression vector (NELL2). (E) PPE mRNA level was determined using real-time PCR analysis after 
transfection with NELL2 expression vector. Bars are the mean \pm SEM of at least 4 wells per group. $* * \mathrm{P}<0.01 ; * * * \mathrm{P}<0.001 ; * * * * \mathrm{P}<0.0001$.

Figure 4. Effect of NELL2 mutants on PPE transcription. (A) Schematic representation of the five NELL2 constructs including naïve NELL2 and NELL2 mutants lacking different domains: NELL2 $\triangle$ TSP-N=mutant NELL2 lacking N-terminal thrombospondin-1-like domain $($ TSP-N); NELL2 $\triangle$ TSP-N-CR=mutant NELL2 lacking TSP-N domain and cysteinerich region of von Willebrand factor $\mathrm{C}$ domains (CR); NELL2 $\triangle \mathrm{EGF}^{-\mathrm{Ca}^{2+}}{ }^{2}=$ mutant NELL2 lacking $\mathrm{Ca}^{2+}$-binding EGF-like domains; NELL2 $\triangle \mathrm{EGF}=$ mutant NELL2 lacking all EGF-like domains. (B) NIH3T3 cells were transfected with PPE-Luc vectors (500 ng) and an equal concentration (300 ng each) of expression vector coding NELL2 or mutant NELL2 constructs as indicated below the figure. The results are expressed as fold change compared to the PPELuc activity in the control pcDNA vector-transfected group (CTL). The results shown are the mean \pm SEM $(\mathrm{n}=6) . * \mathrm{P}<0.05 ; * * \mathrm{P}<0.01 ; * * * \mathrm{P}<0.001$

Figure 5. Intracellular NELL2 action on $\mathrm{Ca}^{2+}$ and PKC-activated ERK, cFos, and PPE expression. (A) Effect of transfected NELL2 or NELL2 $\triangle \mathrm{EGF}-\mathrm{Ca}^{2+}$ expression vector on the $\mathrm{Ca}^{2+}$ ionophore A23187-induced PPE-Luc activity. Luc activity was determined at $1 \mathrm{~h}$ after ionophore treatment. Data represent the mean \pm SEM (n=6). (B) Effect of NELL2 on PMAinduced PPE-Luc activity. Cells were transfected with PPE-Luc vector and NELL2 expression vector with or without treatment of BFA (200 ng) for $24 \mathrm{~h}$, and PMA (100 nM) was applied for $3 \mathrm{~h}$ before harvesting cells. $\mathrm{n}=6$. (C) Effect of NELL2 on PMA-induced phosphorylation of ERK (pERK) in NIH3T3 cells. Cells transfected with expression vector NELL2 or NELL2 $\triangle \mathrm{EGF}^{-\mathrm{Ca}^{2+}}$ were treated with PMA $(100 \mathrm{nM})$ for $30 \mathrm{~min}$ and harvested for western blotting. (D) Effect of NELL2 or NELL2 $\triangle \mathrm{EGF}^{-\mathrm{Ca}^{2+}}$ expression vector on PMA- 
induced cFos expression in NIH3T3 cells. Proteins extracted from the cells treated with PMA for $3 \mathrm{~h}$ were analyzed using western blotting. (E-G) Effect of NELL2 on cFos-Luc activity. The cFos-Luc vector was transfected into NIH3T3 cells together with NELL2 or NELL2 $\triangle$ EGF-Ca ${ }^{2+}$ expression vector. The cells were harvested for Luc assays at $24 \mathrm{~h}$ after transfection. (E) A dose-dependent increase in cFos-Luc activity in cells transfected with different concentrations of cFos-Luc vector. (F) cFos-Luc activity was decreased by NELL2 expression vector in a dose-dependent manner. $(\mathrm{G})$ Effect of NELL2 expression vector on the PMA-induced increase of cFos-Luc activity. NIH3T3 cells were co-transfected with cFosLuc vector (500 ng) and the expression vector (300 ng). One day after transfection, cells were treated with PMA $(100 \mathrm{nM})$ at $3 \mathrm{~h}$ before harvest. CTL $=$ cells transfected with control pcDNA vector. The results shown are the mean \pm SEM $(\mathrm{n}=6) . * \mathrm{P}<0.05 ; * * \mathrm{P}<0.01$; $* * * \mathrm{P}<0.001$.

Figure 6. Effect of extracellular NELL2 on phosphorylation of ERK and PPE transcription. (A) Effect of synthetic NELL2 (sNELL2, $300 \mathrm{ng} / \mathrm{ml}$ ) added to culture medium on phosphorylation of ERK (pERK). Cells were harvested at the indicated time after sNELL2 treatment, and protein extracts were analyzed by western blotting. (B) Increase of PPE-Luc activity by treatment with sNELL2. Luc activity was determined at $24 \mathrm{~h}$ after sNELL2 treatment. The results shown are the mean $\pm \operatorname{SEM}(\mathrm{n}=6) . * * * \mathrm{P}<0.001$.

Figure 7. Effect of in vivo inhibition of NELL2 synthesis on PPE mRNA level in the brain. To determine in vivo disruption of NELL2 synthesis on PPE expression in the brain, antisense-oligodeoxynucleotide (AS-ODN) against NELL2 mRNA was icv injected into the lateral ventricle of 2-month-old male rat brain, and NELL2 protein and PPE mRNA expression was measured by western blot and northern blot analyses, respectively. (A) 
Western blots showing the effectiveness of AS-ODN on the suppression of NELL2 protein content in the hypothalamus. $\beta$-Tubulin was used as an internal control. (B and C) Northern blot analyses showing an increase in PPE mRNA level by treatment with AS-ODN in the hypothalamus (B) and piriform cortex (C). Glyceraldehyde-3-phosphate dehydrogenase $(\mathrm{GAPDH})$ was used as an internal control. Each point represents the mean \pm SEM $(n=6)$. $* * \mathrm{P}<0.01 ; * * * \mathrm{P}<0.001 . \mathrm{SCR}-\mathrm{ODN}=$ scrambled $\mathrm{ODN} ; \mathrm{AU}=$ arbitrary units. 
Supplementary Figure 1. Relative content of NELL2 protein after transfection of cells with NELL2 expression vector. (A, B) NIH3T3 cells were transfected with NELL2 (A) or NELL2KDEL (B) expression vector (300 ng each), and proteins from cell extracts (CE) and culture medium (ME) were analyzed by western blotting with NELL2 antibodies. (C) Effect of brefeldin A (BFA, $200 \mathrm{ng}$ ) on the relative content of NELL2 in CE and ME derived from NIH3T3 cells transfected with the indicated amount of NELL2 expression vector.

Supplementary Figure 2. Effect of NELL2 on the PPE-Luc activity in C17.2 cells. The PPE-Luc (500 ng) was transfected into C17.2 cells with NELL2 (A) or NELL2-KDEL (B) expression vectors at the concentrations indicated. The cells were harvested for Luc activity assays at $24 \mathrm{~h}$ after transfection and relative PPE-Luc activity is shown. The results shown are mean $\pm \operatorname{SEM}(\mathrm{n}=6) . * \mathrm{P}<0.05 ; * * \mathrm{P}<0.01 ; * * * \mathrm{P}<0.001$. 